\title{
Editorial
}

\section{Identifying and quantifying methamphetamine in hair samples}

\author{
David D. Celentano ${ }^{\mathrm{a}}$, Susan G. Sherman ${ }^{\mathrm{a}}$, Robin James Storer ${ }^{\mathrm{b}}$ \\ ${ }^{a}$ Department of Epidemiology and Health, Behavior and Society, Johns Hopkins Bloomberg School of \\ Public Health, Baltimore, Maryland, USA \\ ${ }^{b}$ Department of Physiology, Faculty of Medicine, Chulalongkorn University, Bangkok 10330, Thailand, \\ Co-editor, Asian Biomedicine
}

In this issue of Asia Biomedicine, Junkuy and colleagues [1] describe a new, economical technique for quantifying levels of methamphetamine and its metabolite, amphetamine, in human hair samples. The method, using solid-phase microextraction with gas chromatography and mass spectrometry (SPME/GCMS), met international standards for analysis of methamphetamine (MA) in hair. A detection rate for MA of $35.5 \%$ from hair samples was derived from young MA users who were participating in a randomized-controlled trial of community mobilization for behavior change in Chiang Mai, Thailand [2]. The highest percentage of positive samples was found among more intensive users, with $43.6 \%$ found among persons who reported having used more than $90 \mathrm{MA}$ tablets in the previous 3 months. The article contributes to the literature in describing a simple, economically efficient technique for chemical validation of methamphetamine use. Hair-based assays have long been developed for a number of drugs, and have been used in both clinical, research, and forensic settings [3].

This study presented a rare opportunity to measure self-reported drug use against confirmatory assays of drug testing in a population where drug use among adolescents and young adults is increasingly common. Few examples of such studies occur among survey samples with low rates of drug use [4]. Although the new method has merit in terms of speed of detection and reduced cost, its low detection rate leads to several distinct lines of concerns about its use in the field. First, it points to issues about the validity of self-reported illicit behavior, which was one reason the authors attributed to the low rate of detection of MA use among participants. Reporting bias is a limitation of self-reported data, but unlike the authors' reasoning, this bias is commonly suspected as being towards the null as a result of under-reporting of a stigmatized behavior. Another reason provided for the low detection rate in this drug-using sample is the low purity of MA in the community, given that the study occurred in the aftermath of a "war on drugs". Another line of questioning addresses the validity of the test itself. If the self-reports were true, then clearly the reliability of a hair testing approach is compromised. The low concordance between self-reported MA use and that detected by SPME/GC-MS raises issues about the epidemiological value of hair testing, despite its obvious appeal.

Compared with drug urine and saliva testing, hair testing is more attractive in its ability to detect the presence of opioids and stimulants over a 3 month period, compared with 12 hours for saliva and several days for urine [5]. Further, hair testing is more economical and less invasive compared with urine and saliva testing. However, that a strand of hair that can be extracted and tested with or without a person's consent, calls into question a number of ethical considerations. There has been significant focus on the logistics and legality of drug testing while the ethical aspects receive far less attention [6]. While the ethics of all types of drug testing have been questioned, hair testing ups the ante by extending the period of drug detection [5]. In essence, it moves from incident drug use detected by urinalysis (that is, urinalysis can only detect drug use in the past several days), to that of prevalence, when the period of detection is extended (in this case up to 3 months), often beyond the scope of that required. An ethical lens is necessary to view the testing in the context of such a highly criminalized drug environment such as that in northern Thailand, with its frequent government crackdowns on drug users [7]. It is important to note that hair testing is not intrinsically unethical, but its use could be [8].

Where can hair testing be best employed? From a forensics perspective, the Society of Hair Testing 
2012 guidelines [9] recommends hair testing in four situations: drug-related deaths, drug-facilitated crimes, child custody, and to detect excessive use. Much research on drug testing was born out of forensic science, where such tests are used to confirm or disprove grounds for arrests and convictions [10, 11]. In this context, these tests often occur without consent if evidence is sufficiently (prima facie) substantial.

After forensics, drug screening in workplaces is the second most common environment in which hair testing can be employed [6, 12]. Hair testing might not be ethical in the workplace because it can expose past drug use, which has no bearing on current employment competence (e.g. safety, and performance). From an epidemiologic perspective, hair testing — if reliable — can provide prevalence estimates of drug use in selected populations. It has a number of logistical appeals compared with urine collection and testing: it is easier to collect than urine, there is minimal storage required, and it is less expensive to transport [13]. The use of hair testing obviates the need to ask about illegal behaviors, which are often subject to under-reporting [14]. However, if recent drug use is at question, the value of hair testing is limited. In any research context, appropriate ethical consent must be obtained before any such testing occurs. Of course, the core ethical question in a research setting is the very validity of the method. Discrepancies between biological assays and self-report of illicit drug use could undermine epidemiological research findings [4].

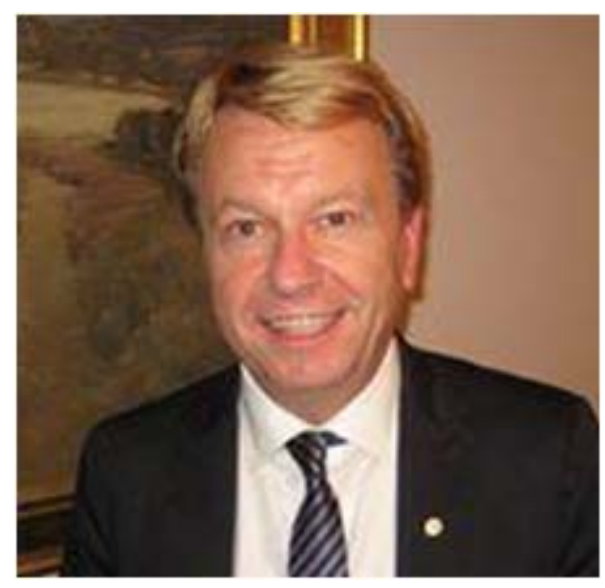

Figure 1. David M. McDowell (1963-2014) with permission.
Finally, this issue is dedicated to David M. McDowell, MD (1963-2014, Figure 1) who served as a reviewer for Asian Biomedicine. Normally reviewers remain anonymous as part of the confidential review process. However, as a tribute to his life and his generosity in reviewing the article on which this editorial is based, we have, with the permission of his family, decided to lift the curtain of anonymity on this occasion. David McDowell was educated at The College of the Holy Cross, where he was valedictorian in the class of 1985, before graduating from the College of Physicians and Surgeons at Columbia University in 1989. In 1995, after his fellowship at New York University Medical Center's Bellevue Hospital, Dr. McDowell joined the faculty of the Department of Psychiatry at his alma mater and co-founded STARS, the Substance Treatment and Research Service at Columbia University, where he served as its medical director until 2004, when he founded the Buprenorphine Program, a highly successful treatment program at Columbia for opiate addiction. In 2008, he joined the faculty of Mt. Sinai Medical Center, New York. His many recognitions include the Excellence in Residency Education Award in 2014 (voted on by graduating residents). His scholarly work has focused on co-occurring psychiatric disorders and substance abuse problems, and his book Substance abuse: from principles to practice [15], is highly regarded. He was certified by the American Board of Psychiatry and Neurology, and named as a Distinguished Fellow by the American Psychiatric Association. A regular guest and contributor to talk shows, magazines, newspapers, and national news organizations, Dr. McDowell consulted widely on a variety of topics and was involved with a number of highly successful plays and films, including Quills and Next to Normal. Dave enjoyed his personal life and had a personality that brightened every room he entered. We were fortunate indeed to have him review the manuscript for Asian Biomedicine before he sadly died in early June after a short battle with pancreatic cancer.

\section{References}

1. Junkuy A, Pengwong M, Aramrattana A, Celentano D, Sribanditmongkol P. Validation and application of hair analysis for the detection of methamphetamine in young Thai adults. Asian Biomed. 2014; 8:463-73.

2. Willard N, Srirojn B, Thomson N, Aramrattana A, Sherman S, Galai N, et al. Coalition formation to address 
structural determinants of methamphetamine use in Thailand. Health promotion international. 2014. Feb 2 e-pub ahead of print doi:10.1093/heapro/dau001.

3. Marsh A, Carruthers ME, Desouza N, Evans MB. An investigation of the effect of washing upon the morphine content of hair measured by a radioimmunoassay technique. J Pharm Biomed Anal. 1992; 10:89-93.

4. Ledgerwood DM, Goldberger BA, Risk NK, Lewis CE, Price RK. Comparison between self-report and hair analysis of illicit drug use in a community sample of middle-aged men. Addictive behaviors. 2008; 33: 1131-9.

5. Strang J, Black J, Marsh A, Smith B. Hair analysis for drugs: technological break-through or ethical quagmire? Addiction (Abingdon, England). 1993; 88: 163-6.

6. American College of Occupational and Environmental Medicine (ACOEM). Ethical aspects of drug testing [on line]. 2009 [cited 2014 August 01]; Position statement, Available from: http://www.acoem.org/ EthicalAspectsOf DrugTesting.aspx\#sthash.Vcj22 XRc.YKSf64P0.dpuf

7. Vongchak T, Kawichai S, Sherman S, Celentano DD, Sirisanthana T, Latkin C, et al. The influence of Thailand’s 2003 ‘war on drugs’ policy on self-reported drug use among injection drug users in Chiang Mai, Thailand. International Journal of Drug Policy. 2005; 16:115-21.

8. Erin CA. Some comments on the ethics of hair analysis for drugs. Addiction (Abingdon, England). 1994; 89:299-300.

9. Cooper GAA, Kronstrand R, Kintz P. Society of Hair Testing guidelines for drug testing in hair. Forensic Science International. 2012; 218:20-4.

10. Stark MM. Further ethical issues raised by hair analysis for drugs. Addiction (Abingdon, England). 1993; 88:1292.

11. Moeller MR, Fey P, Sachs H. Hair analysis as evidence in forensic cases. Forensic Sci Int. 1993; 63:43-53.

12. Sunshine I. Mandatory drug testing in the United States. Forensic Science International. 1993; 63:1-7.

13. Brewer C. Hair analysis for monitoring drug use. Addiction (Abingdon, England). 1993; 88:1291-2.

14. Harrison ER, Haaga J, Richards T. Self-reported drug use data: what do they reveal? The American journal of drug and alcohol abuse. 1993; 19:423-41.

15. McDowell DM, Spitz HI. Substance abuse: from principles to practice. Philadelphia: Brunner-Mazel; 1999. 